\title{
Correction to: Physical prognostic factors predicting outcome following lumbar discectomy surgery: systematic review and narrative synthesis
}

\author{
Alison Rushton ${ }^{1 *}$, Konstantinos Zoulas ${ }^{2}$, Andrew Powell ${ }^{3}$ and J B Staal ${ }^{4,5}$
}

\section{Correction}

Following publication of the original article [1], the author reported that the tagging of their name had been done incorrectly during production process. The original article has been corrected.

\section{Incorrect tagging: \\ Bart Staal J \\ Correct tagging: \\ Staal JB}

\section{Author details}

'Centre of Precision Rehabilitation for Spinal Pain [CPR Spine] School of Sport, Exercise and Rehabilitation Sciences, University of Birmingham, Birmingham B15 2TT, UK. ${ }^{2}$ Polyclinic of Lisieux, Lillebonne, France. ${ }^{3}$ ARC Physiotherapy, Saffron Walden, UK. ${ }^{4}$ Radboud Institute for Health Sciences, IQ healthcare, Radboud UMC, Nijmegen 6500 HB, The Netherlands. ${ }^{5}$ Research group Musculoskeletal Rehabilitation, HAN University of Applied Sciences, Nijmegen, the Netherlands.

Published online: 15 October 2018

\section{Reference}

1. Rushton A, et al. Physical prognostic factors predicting outcome following lumbar discectomy surgery: systematic review and narrative synthesis. BMC Musculoskelet Disord. 2018;19:326. https:/doi.org/10.1186/s12891-018-2240-2.

\footnotetext{
* Correspondence: a.b.rushton@bham.ac.uk; https://www.bham.ac.uk ${ }^{1}$ Centre of Precision Rehabilitation for Spinal Pain [CPR Spine] School of Sport, Exercise and Rehabilitation Sciences, University of Birmingham, Birmingham B15 2TT, UK

Full list of author information is available at the end of the article
} 